\title{
Adaptation of Tectonic Earthquakes Precursors for the Prediction of the Mining-Induced Seismicity During Mining Operations
}

\author{
A.A. Kozyrev, V.I. Panin, V.A. Maltsev, I.V. Fedotova \\ Mining Institute, Kola Science Centre, Russian Academy of Sciences, Russia \\ V.S. Svinin Joint Stock Company "Apatit", Kirovsk, Russia
}

\begin{abstract}
A number of seismic precursors such as concentration; fractal dimension of spatial distribution of seismic events and repeatability slope have been estimated to predict mining-induced seismicity in the Khibiny apatite ore mines conditions. A combined use of several precursors increases the reliability of prediction. To locate the most prone-to-rockburst sites, whose level of damage is determined by the probability of a dynamic event occurrence, is quite a performable task.
\end{abstract}

\section{INTRODUCTION}

The problem of mining-induced seismicity is still real for many countries with the developed mining industry. This is proved by the studies presented at five international symposia on mine rockbursts and mine seismicity held in Johannesburg, 1982; Minneapolis, 1988; Kingstown, 1993; Krakow, 1997; Johannesburg, 2001.

Similarity in physical nature of both dynamic events observed in mines and natural tectonic earthquakes has determined the general use of seismological theoretical models, methods and tools in rockbursts and mininginduced seismicity prediction. In recent years, however, it has become difficult for seismology to obtain solutions to some problems connected with short-term earthquake prediction (Geller, 1996; Leary, 1996).

The main reason for this situation is heterogeneity and non-linearity of a geological structure. In this connection we have suggested and substantiated a model of the geological structure evolution in a mining nature-engineering system and of dynamic events occurring in mines (Kozyrev et al., 1996; Melnikov et al., 2001). According to the model, a hazardous dynamic event is going to occur in some area of the mine when energy concentration in this area reaches some critical level.

Thus, to predict the geodynamic event manifestation means to delineate critically energy saturated zones whose level of criticality is determined by the probability of a powerful dynamic event occurrence. To solve this task, some seismological precursors have been applied.

\section{RESEARCH METHOD}

\subsection{A Combined Prediction Approach}

The area under study has been preliminary divided into spatial cells according to the level of the stationary conditional probability of hazardous event occurrence. If the data on stationary conditional probability is not available, then, on the basis of seismostatistics, only absolute probability is estimated whose values are taken equal for all the cells of the investigated area. The value of conditionally probable state of damage, using a precursors set, is calculated by the Bayes theorem (Zavialov et al., 1995).

$$
P\left(S_{1} \mid K\right)=\frac{P\left(S_{1}\right) \prod_{i=1}^{n} P\left(K_{i} \mid S_{1}\right)}{P\left(S_{1}\right) \prod_{i=1}^{n} P\left(K_{i} \mid S_{1}\right)+P\left(S_{2}\right) \prod_{i=1}^{n} P\left(K_{i} \mid S_{2}\right)}
$$

Where $P\left(S_{1}\right)$ is the absolute (or conditional) stationary probability of state-of-damage emergence in the given spatial window (event $\left.S_{1}\right) ; P\left(S_{2}\right)=1-P\left(S_{1}\right)$ is the absolute (or conditional) stationary probability of the state-of-damage absence in the given spatial window (event $\left.S_{2}\right) ; P\left(K_{i} \mid S_{1}\right)$ is the conditional probability of the appearance of precursor $K_{i}$ after which the state-of-damage has appeared in the given spatial cell (the probability of prediction). $P\left(K_{i} \mid S_{2}\right)$ is the conditional probability of the appearance of precursor $K_{i}$ after which the state-of-damage has not appeared in the given spatial cell (the probability of false alarm); $n$ is the number of precursors.

The value of conditional probability is calculated for each spatial cell into which the area under study is divided. The cells can be either partially overlapped or adjacent.

\subsection{Precursors}

Many seismic and rockmass strain parameters as well as the local methods measurement results can be used as precursors. Of all the precursors, the most known and tested at the Kirovsky mine, "Apatit" Joint Stock Company (JSC), are:

- Stationary signs:

- The working excavation boundaries;

- Dislocations with a break in continuity.

- Non-stationary signs:

- Concentration criterion;

- Fractal dimension of spatial distribution of seismic events;

- Repeatability slope.

Let's consider each of them briefly.

The prediction concentration criterion is based on the kinetic theory of strength according to which solid material failure is not a momentary act but a process evolving in time and depending on the material characteristics, loading process and temperature (Zhurkov et al., 1981). The final failure of a solid material, i.e. a fault formation, is preceded by the volume progressive failure process when microfractures accumulate and coalesce. It has been established that the microfracturing-to-macrofracturing transition is going on according to the concentration criterion:

$$
K=N^{-1 / 3} / L
$$

where $N$ is the number of fractures in a unit of volume; $L$ is the average length of fractures.

The loaded object is broken into fragments or a fault is formed when fracture concentration in a certain volume of 
a solid material reaches a limiting level. The average value of the concentration criterion under the failure of different material samples, is $K=3-5$.

Using this criterion, the length (L) of fractures formed in a rockmass has been calculated from the seismic event energy (E) (Seismicity in mining, 2002):

$$
L=0.1525 \cdot E^{0.3635}
$$

The criterion has been determined in a $200 \times 200 \times 200 \mathrm{~m}^{3}$ window, with a $100 \mathrm{~m}$ shift in each step in a horizontal plane. Each time, after seismic event of $>10^{5} \mathrm{~J}$ is recorded in a cell, this criterion was calculated again.

The criterion of fractal dimension of spatial distribution of seismic events (D) equal to

$$
D=\log C(r) / \log r
$$

where $\mathrm{C}(\mathrm{r})$ is the correlation integral of the hypocentral distribution of seismic events $\left(p_{1}, p_{2}, \ldots, p_{N}\right)$ for the radii ranging from 50 to $250 \mathrm{~m}$ (Xie and Pariseau, 1993):

$$
C(r)=\frac{\sum_{\left|p_{i}-p_{j}\right|<r}^{N} N_{\text {pair }}\left(p_{i}, p_{j}\right)}{N^{2}}
$$

Where $N_{\text {pair }}$ is the number of pairs of events being less than $r$ distant from each other; $N$ is the total number of events.

The fractal dimension probably decreases before the hazardous seismic event occurrence. That the fractal dimension decreases before the quake means, from the physical point of view, that most seismic events concentrate in a narrow zone in the vicinity of the future earthquake epicentre. It has been established that before the quake most events concentrate within the $50-80 \mathrm{~m}$ radius of the spatial distribution of events (Seismicity in mining, 2002).

The slope of repeatability (Gutenberg-Richter relation), whose value has been calculated by a maximum likelihood method by the equation suggested in (Zavialov et al., 1995), can also serve as a precursor of hazardous seismic events within mine fields of JSC "Apatit":

$$
\gamma=\lg \left(1+\frac{N_{\Sigma}}{\sum_{n=1}^{\infty} n \cdot N\left(K_{\min }+n \cdot \Delta K\right)}\right) / \Delta K
$$

Where $N_{\Sigma}$ is the total number of seismic events; $n=1,2,3, \ldots ; N\left(K_{\min }+n \cdot \Delta K\right)$ is the number of seismic events in the energy classes interval ranging from $K_{\min }$ to $n \cdot \Delta K$.

\subsection{Statistical Parameters}

The following parameters are calculated for each precursor:

- Average time duration of alarms;

- Average time duration of false alarms;

- Probability of prediction;

- Probability of false alarm;

- Probability of misgoal;

- Efficiency of prediction in time and in area.

To determine the statistical parameters of each precursor $K$ the following actions have been done:

Time graphs were plotted for the behaviour of each parameter within each spatial cell and with strong seismic events (SSE) marked within each spatial cell considered (Fig. 1).

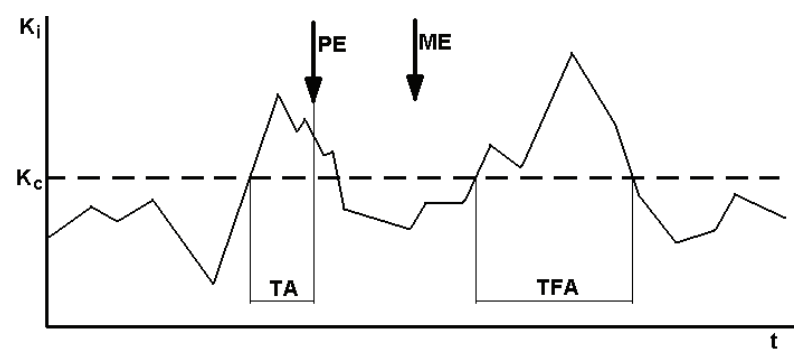

FIG. 1 Precursor $K_{i}$ variation in time TA is time duration of alarms; TFA is time duration of false alarm; PE is events predicted; ME is misgoal (an unpredicted event); $K_{c}$ is the critical level for the given precursor

An average alarm time $\bar{T}_{d t}$ before a SSE:

$$
\bar{T}_{a l}=\Sigma T_{a l} / N_{p}
$$

$N_{p}$ - the number of the SSEs predicted.

The SSE alarm square per time $\bar{T}_{d t}$ :

$$
S_{a l}=S_{c} \cdot \bar{T}_{a l} \cdot N_{p} / T_{t o t}
$$

$S_{c}$ - the spatial cell square into which the area investigated is divided;

$T_{\text {tot }}$ - the total duration of observations.

The area which would have to be covered by alarms $S_{a l}^{*}$ over the alarm time:

$$
\bar{T}_{a l} \cdot S_{a l}^{*}=S_{c} \cdot \bar{T}_{a l} \cdot\left(N_{p}+N_{m}\right) / T_{t o t}
$$

$N_{m}$ - the number of misgoals.

An average duration of faulse alarms $N_{f . a l}$ is calculated from:

$$
\bar{T}_{f . a l}=\Sigma T_{f . a l} / N_{f . a l}
$$

The probability of that a SSE will occur within the $S_{d t}$ (detection probability) is equal to:

$$
P\left(K_{i} / D 1\right)=N_{p} / N_{s}
$$

were $N_{s}$ - the total number of SSEs.

The probability of that a SSE will not occur within the $S_{d t}$ (false alarm probability):

$$
P\left(K_{i} / D 2\right)=S_{f . a l}^{*} /\left(S_{t o t}-S_{a l}^{*}\right)
$$

The alarm square over the observation period:

$$
S_{a l}=S_{a l}^{*}+S_{f . a l}^{*}
$$

An average alarm time per one spatial cell:

$$
\bar{T}_{a l}=\left(\Sigma T_{a l}+\Sigma T_{f . a l}\right) / N_{c}
$$

$N_{c}$ - the number of cells.

The ratio of an average alarm time per one cell to the observation time duration:

$$
L_{t}=\bar{T}_{a l} / T_{t o t}
$$

The ratio of an average alarm square $S_{d t}$ to the total observation square:

$$
L_{s}=S_{a l} / S_{t o t}
$$


The efficiency of prediction using the precursor $K_{i}$ by the time:

$$
I_{t}=P\left(K_{i} / D 1\right) / L_{t}
$$

The efficiency of prediction using the precursor $K_{i}$ by the square:

$$
I_{s}=P\left(K_{i} / D 1\right) / L_{s}
$$

After that, using a set of precursors a conditional probability of the seismic event occurrence has been on-line calculated [1] for each spatial cell.

\section{SOME RESULTS OF PREDICTION}

Firstly, we have analysed only two criteria - concentration and fractal dimension. To give a retrospective assessment of the statistical characteristics of the precursors parameters, the KirovskmineCASM database was used. The databaseincludes seismic events up to $10^{7} \mathrm{~J}$ recorded in 1987-2001, which were classified into two groups, i.e. those to be predicted $\left(10^{5}-10^{7} \mathrm{~J}\right)$ and those $\left(10^{3}-10^{5} \mathrm{~J}\right)$ on whose analysis a prediction has been made. The value of conditional probability $P\left(S_{1} \mid K\right)$ [1] was calculated for each of 24 overlapping spatial $200 \times 200 \times 200 \mathrm{~m}^{3}$ cells into which the area covered by the CASM was divided. The adjacent cells have been $50 \%$ overlapped. In making prediction used was an event window, with its shifting in the time axis to one event. Consideration was given to 15 , 20 and 30-event windows to clear out at what number of events the prediction is the most stable in the Khibiny mines conditions.

In optimising the prediction parameters by the concentration and fractal criteria, it was established that, using the concentration criterion, the best result was with a 20-event window and with the critical level 5. Using the fractal criterion, the best variant was with a 20-event window and with the critical level 0.8. In making prediction by the concentration criterion and by the critical level 5 , $P\left(K_{1} \mid S_{1}\right)=0.55$ and $P\left(K_{1} \mid S_{2}\right)=0.14$. In making prediction by the fractal criterion and the critical level $0.8, P\left(K_{2} \mid S_{1}\right)=0.31$ and $P\left(K_{2} \mid S_{2}\right)=0.08$. The total probability of the seismic events occurrence was calculated by the equation [1].

Figure 2 shows the prediction results obtained by the two criteria.

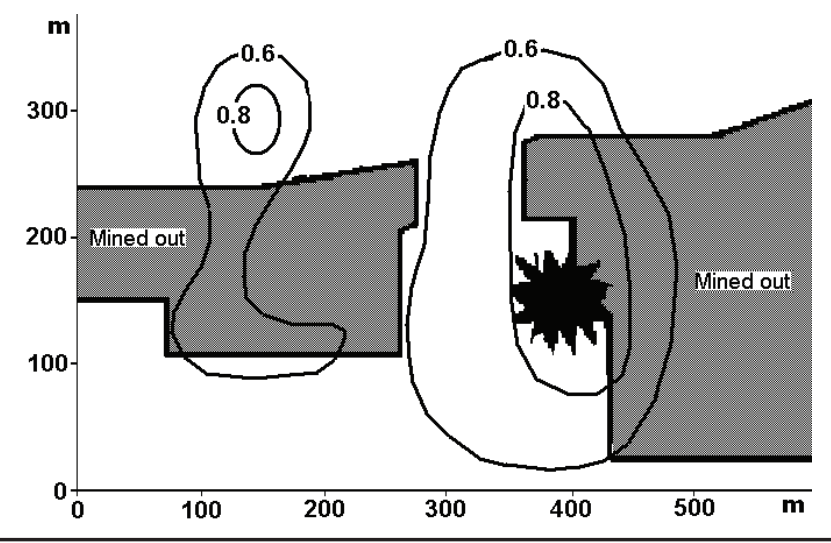

FIG. 2 Mining-induced earthquake (November 11, 1993) occurrence probability isolines based on the retrospective analysis of concentration and fractal dimension criteria

- the stope boundaries

- the mining-induced earthquake focus

Figure 2 shows that the mining-induced earthquake focus is in the area where the criteria considered exceed the critical level simultaneously. Using, however, only two non-stationary criteria at the horizon mined, there are great areas left with small absolute probability. It is known, however, that most seismic events are confined to the boundaries of working excavations or of geological dislocation. So, as an extension of the approach adopted in prediction, consideration has been given to two stationary signs such as the working excavation boundaries influence and the geological dislocations boundaries. Calculated for the two signs was the value of the conditional stationary probability of hazardous seismic event occurrence. In so doing, the CASM zone was divided into non-overlapped $50 \times 50 \mathrm{~m}$ squares. As the experience shows, the maximum number of seismic events occurs in the zones of stress concentration, which are adjacent to the mined out area boundaries and geological dislocations. The mined out area and geological dislocation disturbance zones in the Khibiny mines conditions are on the average are $\pm 25 \mathrm{~m}$ and $\pm 50 \mathrm{~m}$, respectively. The probability values for the boundaries of the mined out area $P\left(K_{1} \mid D_{1}\right)=0.67$ and $P\left(K_{1} \mid D_{2}\right)=0.33$ and geological dislocations are $P\left(K_{2} \mid D_{1}\right)=0.34$ and $P\left(K_{2} \mid D_{2}\right)=0.33$, respectively.

To estimate statistic parameters by the repeatability slope in terms of a retrospective look, the seismic regime parameters were calculated in rectangular elements of the mesh whose size was $100 \times 100 \mathrm{~m} 2$. This size of the elements allowed sufficient calculation of statistics for the events of representative energy classes $\mathrm{K} \geq 3.0$. The designed values of the repeatability slope, obtained in the elements, are in the range of $0.164 \leq \gamma \leq 0.468$.

The Table shows the assessment results of the total probability of prediction of hazardous seismic events by a set of various precursor combinations.

Taking into account the stationary signs, the mininginduced earthquake prediction results, which were shown in Figure 2, are transformed into the mining-induced earthquake prediction results shown in Figure 3. In Figure 3 the zone of an increased probability of the earthquake occurrence is more clearly revealed and the zone in which the probability is of 0.2-0.4, appears along the mined out area boundaries.

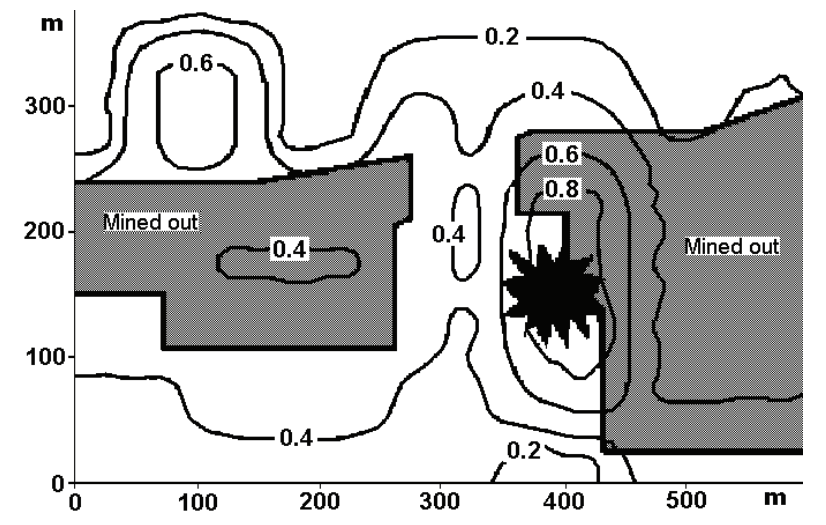

FIG. 3 Mining-induced earthquake (November 11, 1993) occurrence probability isolines based on the retrospective analysis of concentration, fractal dimension criteria and two stationary criteria (the influence of the mined out area boundary and geological dislocations)

Figures 4 and 5 show the prediction results of tectonic rockburst (TRB) in block 10/14, the Kirovsky mine, in 2001 (maps of probable TRB occurrence). By the beginning of the year 2001 at the working excavation boundary (sections 10-12) there was formed a zone with a higher probability 0.8 of the hazardous earthquake occurrence and the zones of moderate probability (0.7-0.6) began to concentrate (sections 10-12 and 12-13). By the moment of occurrence of TRB (Feb.15, 2001) and its aftershock (Feb.17, 2001), much more concentration of moderate zones took place. The prediction results at the 
TABLE 1 The probability of SSE-occurrence under various precursors combinations ap is absolute probability; web is working excavation boundaries; $f$ is faults; $f c$ is fractal criterion; $c c$ is concentration criterion and $r s$ is repeatability slope

\begin{tabular}{|c|c|}
\hline Probability combination & Total probability \\
\hline ap & 0.05 \\
\hline$a p+f$ & 0.051 \\
\hline$a p+$ web & 0.102 \\
\hline$a p+w e b+f$ & 0.104 \\
\hline$a p+f c$ & 0.169 \\
\hline$a p+f+f c$ & 0.173 \\
\hline$a p+c c$ & 0.171 \\
\hline$a p+f+c c$ & 0.175 \\
\hline$a p+w e b+f c$ & 0.306 \\
\hline$a p+w e b+f+f c$ & 0.311 \\
\hline$a p+w e b+c c$ & 0.309 \\
\hline$a p+w e b+f+c c$ & 0.314 \\
\hline$a p+f c+c c$ & 0.445 \\
\hline$a p+f+f c+c c$ & 0.450 \\
\hline$a p+w e b+f c+c c$ & 0.634 \\
\hline$a p+w e b+f+f c+c c$ & 0.639 \\
\hline $\mathrm{ap}+\mathrm{rs}$ & 0.103 \\
\hline$a p+r s+w e b$ & 0.199 \\
\hline$a p+r s+f$ & 0.102 \\
\hline$a p+r s+f c$ & 0.308 \\
\hline$a p+r s+c c$ & 0.311 \\
\hline$a p+r s+w e b+f$ & 0.203 \\
\hline$a p+r s+w e b+f c$ & 0.490 \\
\hline$a p+r s+w e b+c c$ & 0.494 \\
\hline$a p+r s+f+f c$ & 0.313 \\
\hline$a p+r s+f+c c$ & 0.316 \\
\hline$a p+r s+f c+c c$ & 0.253 \\
\hline$a p+r s+w e b+f+f c$ & 0.496 \\
\hline$a p+r s+w e b+f+c c$ & 0.499 \\
\hline$a p+r s+f+f c+c c$ & 0.641 \\
\hline$a p+r s+w e b+f c+c c$ & 0.791 \\
\hline$a p+r s+w e b+f+f c+c c$ & 0.794 \\
\hline
\end{tabular}

moment of the TRB (Feb. 15, 2001) are shown in Figure 4. Hypocentres of these events are in the boundaries of the zones of probability $0.8,(0.7-0.6)$ and in the boundaries of the working excavation influence.

The tectonic rockburst caused roof slabs to fall down, fracturing the rockmass surrounding the mine works and causing pillar collapse.

Figure 5 shows a map of probabilities of strong seismic events (SSE) occurrence in the same sections in the late 2001.

The data from Figure 5 indicate that seismic activity at the site under consideration decreased significantly at the end of the year, the zone of an increased probability (0.8) has disappeared, and the zone of moderate probability (0.6) is of a minimum size. The seismic event of $\mathrm{E}>10^{5} \mathrm{~J}$ took place in the boundaries of the zones (0.6 and 0.4 ).

Thus, in calculating the total probability of seismic events occurrence the best result is when prediction is made when all the set of criteria work well. A greater number of the criteria used allow the zone under control to be differentiated in much more detail in terms of probability of hazardous seismic events occurrence.

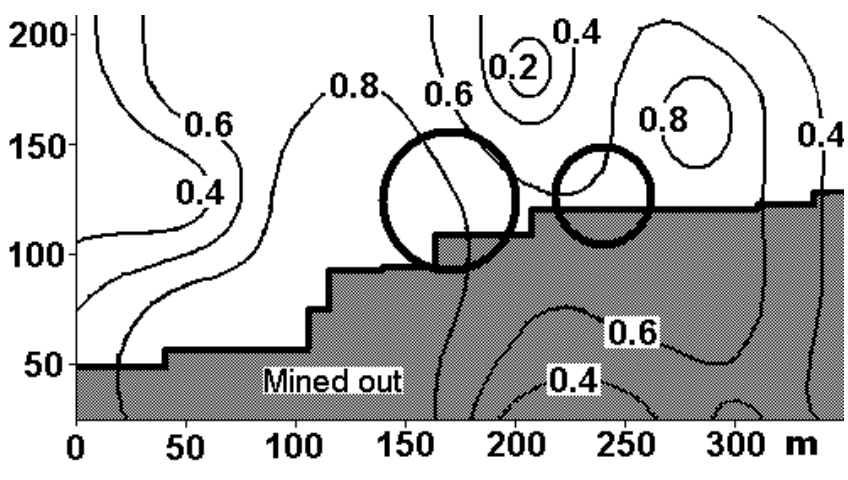

FIG. 4 The map of probable tectonic rockburst in block 10/14 the Kirovsky mine part (February 15, 2001 - a large circle) and its aftershock (February 17, 2001 - a small circle)

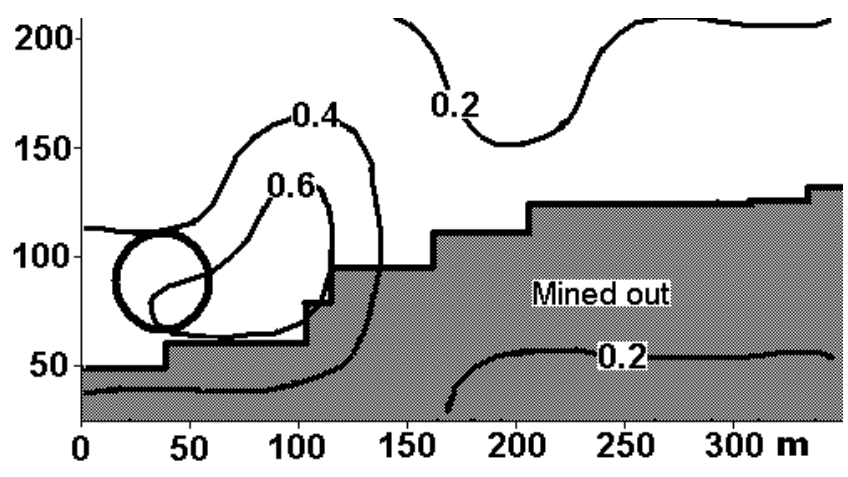

FIG. 5 The map of probabilities of HSE in block 10/14, the Kirovsky mine wing in the late 2001 (Dec.12, 2001)

\section{ANALYSIS OF THE RESULTS}

High quantity of false alarms is due to blasting operations carried out in mine. This can be eliminated by imposing a prohibition on alarms at the beginning of the relaxtion sequence of seismic events (duration which is fixed on reduction seismicity before background level preceded blast) induced by blasting. The period of relaxation determined as a period of decrease in the seismicity level up to the background level for the Khibiny mines is about 1-2 days. If used in the regions of different mining-and-geological conditions, the integrated prediction methods should be adapted to them.

Note should be taken also of instability when working with small number of events (5-7) in window, which is a characteristic feature of all the statistic models. In increasing the window size, instability disappears but the probability of missing goal is also due to the feature of the method, which is designed to predict in a quasi-continuous rockmass under the natural evolution of a hazardous earthquake.

It should be noted that the prediction results of 1993 and 2001 have the best indices on the criteria said. During the period between 1991 and 2002 the efficiency of the prediction indices was not over 2-5. It is probably due to the fact that there were no significant mining-induced dynamic effects, on the rockmass, and all the processes took place in a quasinatural regime. In the period foregoing-to-1993, natural rock failure processes were broken by bulk blasting. Moreover, most blasting was carried out in the vicinity of the fault, so most powerful seismic events resulted from movements along that fault. After 1993, ore mining activity in the region under discussion was suspended and in the undermined console of the hangingwall rock, a great rupture fracture began to form. 
The mechanisms of evolution and occurrence of seismic events induced by movements along the faults or by the development of a rupture fracture in the hangingwall rock console are of the other nature than that of the development of a failure in a quasi-continuous zone of a rockmass which is under minimum mining-induced effect. Movements along the faults are often preceded by a seismic quiescence, and the rupture fracture develops in the rock console under the effect of its own weight in chaos either during ore drawing from under the console and failure of rock supporting the console, or during blasting. That the events with so different mechanisms of occurrence are included into the analysis decreases the efficiency of prediction by the criteria considered, the prediction that is more intended for the natural course of events in a quasi-continuous rockmass.

Thus, based on the seismicity monitoring data it is possible to reliably delineate zones prone to dynamic manifestations. As for the probability of the hazardous seismic events occurrence in these zones, it should be considered as the level of hazard (criticality) which determines the time of the beginning of implementation of the appropriate preventive measures (Seismicity in mining, 2002).

\section{CONCLUSION}

The results of the retrospective analysis regarding the efficiency of seismic precursors, taking the geomechanic setting in the mine into account, show about $80 \%$ probability of prediction under the most favourable conditions (some idealised geological environment, the information available about the stope boundaries and tectonics). The technological parameters used in prediction (i.e. alarm time, faulse alarms, etc) under the operating mine conditions often turn out to be unacceptable. Meantime, prediction of strong seismic events in mines must be close to $100 \%$ but, in the nearest future it seems practically impossible. However, according to the studies carried out it is possible to carry out seismic zoning. The level of risk is determined in this case by the probability of strong seismic events occurrence in these areas. So, it is necessary to evaluate the risk caused by these events and, based on the risk value, one may determine strategy and tactics of mining operations. Similar tendencies one can observe in the current seismology where more and more attention is paid to studies aimed at seismic risk evaluation and seismic zoning, which results in optimisation of parameters for antiseismic construction.

Further activity on improvement of prediction should be aimed at the substantiation of special criteria for each mechanism of the failure development. In so doing, the prediction of each of the mechanisms considered will be more effective if several parameters mutually complementing each other are under concurrent control.

\section{ACKNOWLEDGMENTS}

This research was supported by Russian Foundation of Basic Research, Grants N 03-05-65258.

\section{REFERENCES}

Geller, R. (1996) Earthquake prediction: a critical review. Geophysical Journal International. Vol. 131, N 3, pp. 425-450.

Kozyrev, A.A., Panin, V.I. and Maltsev, V.A. (1996) Study of the geodynamic regime of the region under large-scale mining in the apatite-nepheline deposits in the Kola Peninsula, Russia. Proceedings of MassMin 200, Brisbare, Qld, 29 october- 2 november 2000, The Abstralasian Institute of Mining and Metallurgy. pp. 799-803.

Kuksenko, V.C., Inzhevatkin, I.Ye. and Manzhikov, B.Ts. (1987) Physical and methodical principles of rockburst prediction. Physical-and-technical problems of mining. N 1, pp. 9-22. (In Rus.).

Leary, P.C. (1996) Rock as a critical-point system and the inherent implausibility of reliable earthquake prediction. Geophysical Journal International. Vol. 131, N 3. pp. 451-566.

Melnikov, N.N., Kozyrev, A.A., Savchenko, S.N., Panin, V.I. and Maltsev, V.A. (2001) Prediction and prevention of rock bursts, tectonic shocks and technogenic earthquakes from positions of nonlinear geodynamics. Journal of mining science. Vol. 37, N 4 pp. 354-366.

Seismicity in mining (2002) Collective of the authors. Apatity, Kola Science Centre RAS. 325 pages (In Russian).

Xie, H. and Pariseau, W.G. (1993) Fractal character and mechanism of rock bursts. Jnt.I.Rock Mech. and Min.Sci., Vol. 30 N 4, pp. 343-350.

Zavialov, A.D., Slavina, L.B.,Vasiliev, V.Yu. and Myachkin, V.V. (1995) Techniques for calculating maps of earthquakes expected by a set of precursors. Moskow. JIPE RAS, 40pages (In Rusian)

Zhurkov, S.K., Kuksenko, V.S. and Petrov (1981) Physical principles of mechanical failure. Pap. of the USSR Ac.Sci., Vol. 259, N 6, pp 13501353 (In Russian). 